\title{
ROLE OF MULTIDETECTOR CT UROGRAPHY IN EVALUATING PATIENTS WITH HAEMATURIA
}

\author{
Varsha Rathi', Swenil Shah², Chaitali Nimbalkar³, Kalyani Patankar ${ }^{4}$
}

${ }^{1}$ Associate Professor, Department of Radiodiagnosis, Indira Gandhi Government Medical College, Nagpur.

${ }^{2}$ Senior Resident, Department of Radiodiagnosis, Indira Gandhi Government Medical College, Nagpur.

3Junior Resident, Department of Radiodiagnosis, Indira Gandhi Government Medical College, Nagpur.

4Junior Resident, Department of Radiodiagnosis, Indira Gandhi Government Medical College, Nagpur.

\section{ABSTRACT}

Haematuria is one of the commonest manifestation of urinary tract pathologies and requires thorough diagnostic workup. MDCT urography with its faster speed and multiplanar capabilities has become the investigation of choice in such cases.

\section{OBJECTIVES}

Our study was done with the aims of assessing the role of CT Urography in detecting the entire spectrum of urinary tract diseases causing haematuria and also to establish whether this single investigation suffices in directing the right management strategy in all these patients.

\section{MATERIALS AND METHODS}

This prospective study of 105 patients presenting with haematuria was done at a tertiary care government hospital at Nagpur over a period of two years. Two phase acquisition protocol (Split Bolus technique) with saline distension was done in the majority of cases. Separate cortico-medullary phase images were acquired in cases of renal neoplasms for their better characterization. Images were viewed in axial as well as with 3D reformatted coronal planes.

\section{RESULTS}

Split bolus MDCT Urography with saline distension provided at least $50 \%$ opacification of urinary tract in about $94.8 \%$. Major causes of haematuria in our study were urolithiasis (25.7\%), Urothelial tract and bladder neoplasms (23.8\%) followed by renal neoplasms (16.2\%). Developmental anomalies, infections and trauma were some other aetiologies. The overall sensitivity for upper urinary tract evaluation was $100 \%$, while that for lower urinary tract was $88.4 \%$. The overall positive predictive value was $97.4 \%$ in diagnosing haematuria by MDCT Urography.

\section{CONCLUSIONS}

CT Urography is highly accurate in evaluation of haematuria and definitely has potential to be one stop shop in evaluation of patients with haematuria. With the use of properly tailored protocols, the issue of radiation exposure can be addressed.

\section{KEYWORDS}

MDCT Urography, Haematuria.

HOW TO CITE THIS ARTICLE: Rathi V, Shah S, Nimbalkar C, et al. Role of multidetector CT urography in evaluating patients with haematuria. J. Evolution Med. Dent. Sci. 2016;5(59):4130-4136, DOI: 10.14260/jemds/2016/944

\section{INTRODUCTION}

Haematuria is one of the most common presentations of urinary tract pathologies and always warrants serious concern, both to the patient as well as the treating physician.1,2 The advanced multidetector CT scanners. ${ }^{3,4}$ with its superior spatial resolution, higher speed and isotropic reconstruction capability has ushered in a revolution in diagnostic imaging of urinary tract disorders. MDCT urography provides a detailed anatomic depiction of the entire urinary tract in a single breath hold, thus allowing patients with haematuria to be evaluated comprehensively. ${ }^{5}$ The superior spatial resolution allows excellent 3D multiplanar reformats. ${ }^{6}$ Lately, it has almost supplanted the conventional urography in evaluation of the urinary tract.3,4,5,6,7

Financial or Other, Competing Interest: None.

Submission 02-06-2016, Peer Review 09-07-2016,

Acceptance 15-07-2016, Published 25-07-2016.

Corresponding Author:

Dr. Varsha Rathi,

Block No. 4, Type 5, Doctors Staff Quarters,

ESIS Hospital, Ganpat Jadhav Marg,

Worli, Mumbai-18.

E-mail:drvpr68@gmail.com

DOI: $10.14260 /$ jemds/2016/944

\section{AIMS AND OBJECTIVES}

- To study the accuracy of CT urography in identifying various pathologies of urinary tract causing haematuria.

- To study the spectrum of imaging findings in patients presenting with gross as well as microscopic haematuria.

- To study whether with a single investigation of CT Urography can assist in formulating the right management strategy in every patient of haematuria.

\section{MATERIAL AND METHODS}

\section{Study Design}

Prospective study, hospital-based study of patients with haematuria was done at a tertiary care institute.

Study Settings: Dept. of Radiodiagnosis, IGGMCH, Nagpur.

Study Period: Sept. 2009-August 2011.

Study Population: 105 patients of all ages referred by the clinicians.

\section{Inclusion Criteria}

1. Complaints of gross haematuria.

2. Documented unresolving microscopic haematuria with associated significant risk factors for developing urologic disease. 
3. Patients with haematuria who were suspected to have some urinary tract pathology on other modalities and were then referred for CT Urography.

4. Patients whose complete medical or surgical treatment follow-up was available.

\section{Exclusion Criteria}

1. Patients lost to follow-up.

2. Patients whose haematuria resolved on subsequent clinical and post medical treatment follow-up.

3. Patients whose serum creatinine value was above $\mathbf{1 . 5}$ $\mathrm{mg} / \mathrm{dL}$

4. Patients known to be allergic to ionic or non-ionic contrast media.

5. Pregnant patients.

\section{Equipment}

1. Somatom Emotion Duo CT Scanner; Siemens Medical Systems, Forchheim, Germany.

2. Medrad Vistron Pressure Injector.

\section{CT Urography Protocol}

- Patient is advised to be nil by mouth six hours before the study.

- Water (800-1000 mL) was given as negative contrast medium.

- An initial supine AP scout film with $100 \mathrm{~mA}$ was obtained to confirm the tomographic plane.

- Precontrast scan was done in supine position using $5 \mathrm{~mm}$ collimation (100 mA, $120 \mathrm{Kv}$, pitch 6) from the domes of diaphragm to the base of the bladder.

A. The Two Phase (Pre-Contrast and Combined Nephropyelographic and Excretory Phase or "Split Bolus" Post Contrast ) Acquisition Protocol.5,8,9,10,11

- Initially, a bolus of $30 \mathrm{~mL}$ of $300 \mathrm{mg} / \mathrm{mL}$ iodinated non-ionic contrast (Inj. Iomeron Bracco, Italy) given intravenously.

- After this, $250 \mathrm{~mL}$ of normal saline was administered intravenously over the next 8-10 minutes for better delineation. ${ }^{11}$ and opacification of ureters.

- Dynamic contrast enhanced scanning using $3 \mathrm{~mm}$ collimation (mAs 150, kV 120) was now performed following administration of additional $80 \mathrm{~mL}$ contrast at $2.3 \mathrm{~mL} / \mathrm{second}$ after a start delay of 80 seconds.

This split bolus two-phase CT Urography technique allowed acquisition in the nephropyelographic phase and was done in the majority of patients.

\begin{tabular}{|c|c|}
\hline Parameters & Value \\
\hline Collimation & $3 \mathrm{~mm}$ \\
\hline Reconstruction Increment & $1 \mathrm{~mm}$ \\
\hline $\mathrm{mAs}$ & 150 \\
\hline $\mathrm{KV}$ & 120 \\
\hline Table Feed & $4 \mathrm{~mm}$ \\
\hline
\end{tabular}

B. The Three Phase Protocol: Separate CorticoMedullary, Nephro-Pyelographic and Excretory Phase Acquisition. ${ }^{12}$
(For Renal Masses, Trauma Cases and those with Suspected Vascular Anomalies we followed this Protocol).

- Initial bolus dose not given.

- Instead, a total of $100 \mathrm{cc}$ of $300 \mathrm{mg} / \mathrm{mL}$ intravenous contrast was administered at a rate of $2.3 \mathrm{~mL} / \mathrm{sec}$ by a pressure injector after a start delay of 24 seconds, 80 seconds and 180 seconds for acquisition of the above phases respectively.

- All the other technical parameters were kept similar to that in the two-phase protocol.

\section{Post Processing and Image Analysis}

Coronal and sagittal reformation of the images was done using Maximal Intensity Projection (MIP), Multiplanar Reformation (MPR) and Volume Rendering Technique (VRT).

The axial as well as reformatted coronal and sagittal images were viewed on a workstation for evaluation.

The images were converted from Dicom to JPEG format using E-film software for storage.

\section{Follow-Up}

A meticulous follow-up of all 105 patients was kept. The standard of reference included all available, clinical, lab results, histopathological and operative findings as well as other imaging modalities like Ultrasound as well as cystoscopy, ureteroscopy, DSA, etc.

The $M / T$ strategy was determined by the clinical judgement of the referring physician.

\section{RESULTS}

\begin{tabular}{|c|c|c|c|}
\hline $\begin{array}{c}\text { Sl. } \\
\text { No. }\end{array}$ & $\begin{array}{c}\text { No. of } \\
\text { Cases }\end{array}$ & Percentage \\
\hline 1. & $\begin{array}{c}\text { Number of } \\
\text { abnormal scans }\end{array}$ & 93 & $88.6 \%$ \\
\hline 2. & $\begin{array}{c}\text { Number of } \\
\text { normal scans }\end{array}$ & 12 & $11.4 \%$ \\
\hline \multicolumn{2}{|c|}{ Total } & $\mathbf{1 0 0}$ & $\mathbf{1 0 0 \%}$ \\
\hline \multicolumn{2}{|c|}{ Table 1: Incidence of Abnormalities on CT Urography } \\
\hline
\end{tabular}

\begin{tabular}{|c|c|c|}
\hline Final Diagnosis & Modality Used & $\begin{array}{c}\text { No. of } \\
\text { Patients }\end{array}$ \\
\hline TCC Bladder & Cystoscopic Biopsy & 3 \\
\hline TCC Lower Ureter & $\begin{array}{c}\text { Ureteroscopic } \\
\text { Biopsy }\end{array}$ & 1 \\
\hline $\begin{array}{c}\text { Intrarenal Arterio- } \\
\text { Venous } \\
\text { Malformation }\end{array}$ & $\begin{array}{c}\text { Digital Subtraction } \\
\text { Renal Angiography }\end{array}$ & 2 \\
\hline Indeterminate & $\begin{array}{c}\text { Relevant According } \\
\text { to Clinical } \\
\text { Presentation }\end{array}$ & 6 \\
\hline \multicolumn{2}{|c|}{ Total } & $\mathbf{1 2}$ \\
\hline \multicolumn{2}{|c|}{ Table 2: Final Diagnosis of Haematuria } \\
Cases with Normal CT Urography \\
\hline \multicolumn{2}{|c|}{}
\end{tabular}

Thus, the sensitivity of CT Urography in identifying a pathology for haematuria was $93.93 \%$ and the positive predictive value was $100 \%$, while the specificity was also $100 \%$ and the negative predictive value was $50 \%$.

\begin{tabular}{|c|c|c|}
\hline Sex & No. of Cases & Percentage \\
\hline Male & 68 & $64.8 \%$ \\
\hline Female & 37 & $35.2 \%$ \\
\hline Total & $\mathbf{1 0 5}$ & $\mathbf{1 0 0} \%$ \\
\hline \multicolumn{2}{|c|}{ Table 3: Gender Distribution of Cases } \\
\hline
\end{tabular}




\begin{tabular}{|c|c|c|c|c|}
\hline \multirow{2}{*}{ Pathologies } & \multirow{2}{*}{ Gross Haematuria } & \multicolumn{2}{|c|}{ Microscopic Haematuria } & \multirow{2}{*}{ Total } \\
\hline & & Asymptomatic & Symptomatic & \\
\hline Urolithiasis & 9 & 0 & 18 & $27(25.7 \%)$ \\
\hline $\begin{array}{c}\text { Urothelial } \\
\text { Tract and } \\
\text { Bladder Neoplasms }\end{array}$ & 10 & 6 & 9 & $25(23.8 \%)$ \\
\hline $\begin{array}{l}\text { Renal Parenchymal Masses } \\
\text { (Benign and Malignant) }\end{array}$ & 8 & 5 & 4 & $17(16.2 \%)$ \\
\hline Developmental anomalies & 1 & 4 & 2 & $\begin{array}{c}7 \\
(6.7 \%)\end{array}$ \\
\hline Infection & 2 & 0 & 5 & $7(6.7 \%)$ \\
\hline Trauma & 5 & 0 & 1 & $6(5.7 \%)$ \\
\hline Vascular Malformations & 0 & 2 & 0 & $\begin{array}{c}2 \\
(1.9 \%)\end{array}$ \\
\hline Extraurinary Tract Pathologies & 2 & 0 & 0 & $\begin{array}{c}2 \\
(1.9 \%)\end{array}$ \\
\hline No Cause Found & 1 & 11 & 0 & $12(11.4 \%)$ \\
\hline Total & 38 & 28 & 39 & 105 \\
\hline
\end{tabular}

Calculus disease was most commonly encountered in young and middle age group (16-45 years), 17 (63\%) cases out of 27.

Non-neoplastic lesions were more common in younger age group ( $<45$ years), while neoplastic lesions were common in older age group ( $>45$ years). Urothelial tract and bladder neoplasms were significantly more common in males, 20 cases $(80 \%)$ out of 25 as compared to in females, 5 cases (20\%).

\begin{tabular}{|c|c|}
\hline Site & No. of Patients \\
\hline Renal Pelvis & $4(16 \%)$ \\
\hline Ureter & $4(16 \%)$ \\
\hline Bladder & $14(56 \%)(1$ benign, 13 malignant $)$ \\
\hline Multifocal & $3(12 \%)$ \\
\hline Total & 25 (100\%) \\
\hline \multicolumn{2}{|c|}{ Table 5: Distribution of Urothelial } \\
Tract and Bladder Neoplasms
\end{tabular}

TCC was the commonest histopathological type of bladder malignancy encountered constituting $96 \%$ of the total, while only one case (4\%) was of squamous cell carcinoma and 1 case (4\%) was of bladder papilloma.

Urothelial tract thickening was more common in pelvicalyceal system lesions, 2 (66.7\%), while endoluminal filling defect was common in ureteral lesions, 3 (100\%). We encountered 3 lesions with an infiltrative pattern of growth; 1 lesion at the pelviureteric junction was included in the pelvicalyceal system lesions. Out of the 5 ureteral neoplasms, 3 were in the lower ureter, while 2 in the upper. Thus, there were 6 upper tract and 3 lower tract neoplasms in all; 1 out of 5 ureteric neoplasms was multifocal with another lesion in bladder.

We could identify 9 out of 10 urothelial tract malignant lesions on CT urography; 1 lesion was diagnosed as lower ureter TCC on ureteroscopic biopsy performed in a patient of haematuria with normal CT Urography examination out of the 9 lesions diagnosed to be malignant on CT Urography, 1 lesion in the lower ureter turned out to be a blood clot on ureteroscopic biopsy and another lesion was an inflammatory focal thickening in the renal pelvis on histopathology).
Thus the overall sensitivity, positive predictive value, specificity and negative predictive value in identifying a urothelial tract neoplasm in our study was $87.5 \%, 77.8 \%$, $66.7 \%$ and $80 \%$ respectively. These values were $100 \%, 83.3 \%$, $75 \%$ and $80 \%$ respectively for upper tract tumours and $66.7 \%$, $50 \%, 66.7 \%$ and $50 \%$ for lower tract tumours respectively.

\begin{tabular}{|c|c|c|c|c|}
\hline & Type & $\begin{array}{c}\text { No. of } \\
\text { Patients }\end{array}$ & Percentage & Total \\
\hline \multirow{4}{*}{ Malignant } & RCC & 5 & $29.4 \%$ & \multirow{4}{*}{$\begin{array}{c}11 \\
(64.7 \%)\end{array}$} \\
\hline & Wilms' & 3 & $17.6 \%$ & \\
\hline & Lymphoma & 2 & $11.8 \%$ & \\
\hline & Sarcoma & 1 & $5.9 \%$ & \\
\hline \multirow{4}{*}{ Benign } & AML & 2 & $11.8 \%$ & \multirow{4}{*}{$\begin{array}{c}6 \\
(35.3 \%)\end{array}$} \\
\hline & Complex cyst & 3 & $17.6 \%$ & \\
\hline & Oncocytoma & 1 & $5.9 \%$ & \\
\hline & Total & 17 & $100 \%$ & \\
\hline & $\begin{array}{r}\text { le 6: Distrib } \\
\mathrm{Nec}\end{array}$ & on of $R e$ & $\begin{array}{l}\text { Parenchy } \\
\text { ns }\end{array}$ & \\
\hline
\end{tabular}

In our study, we could identify all renal parenchymal benign and malignant lesions which were a potential cause of haematuria of varying degrees in these patients. We could also stage the malignant lesions with fair degree of accuracy. We could identify one subcentimeter sized RCC's and one subcentimeter sized lymphoma in our study. One patient with renal cell sarcoma actually had a high-grade TCC on histopathological examination. We had $100 \%$ sensitivity and $94.1 \%$ positive predictive value in diagnosing renal parenchymal masses by CT urography.

\begin{tabular}{|c|c|c|c|c|}
\hline $\begin{array}{c}\text { Sl. } \\
\text { No. }\end{array}$ & $\begin{array}{c}\text { Developmental } \\
\text { Anomaly }\end{array}$ & $\begin{array}{c}\text { Actual Cause of } \\
\text { Haematuria }\end{array}$ & $\begin{array}{c}\text { No. of } \\
\text { Cases }\end{array}$ & \multirow{2}{*}{ Total } \\
\hline \multirow{3}{*}{1} & \multirow{3}{*}{ Horseshoe Kidney } & Neoplasm & 1 & \multirow{2}{*}{5} \\
\cline { 3 - 4 } & & Trauma & 1 & \multirow{2}{*}{5} \\
\cline { 3 - 4 } & & Calculus & 1 & \multirow{2}{*}{5} \\
\cline { 3 - 4 } 2 & \multirow{2}{*}{ PUJ Obstruction } & No Cause & 2 & \\
\cline { 3 - 4 } & & Calculus & 2 & 1 \\
\hline
\end{tabular}




\begin{tabular}{|c|c|c|c|c|}
\hline \multirow{2}{*}{3} & & Infection & 1 & \\
\cline { 3 - 4 } 3 & No & No Cause & 1 & \\
\hline \multirow{2}{*}{4} & $\begin{array}{c}\text { Adult polycystic } \\
\text { Kidney }\end{array}$ & Calculus & 1 & \multirow{2}{*}{2} \\
\cline { 3 - 4 } & No Cause & 1 & \\
\hline 5 & Ectopic Kidney & No Cause & 1 & 2 \\
\hline \multicolumn{4}{|c|}{ Table 7: Spectrum of Developmental } \\
Anomalies Encountered \\
\hline
\end{tabular}

Horseshoe kidney and pelviureteric junction obstruction were most commonly seen anomalies. The above table shows that 8 of the 15 patients with developmental anomalies had some predisposing cause for haematuria.

\begin{tabular}{|c|c|c|}
\hline & $\begin{array}{c}\text { No. of } \\
\text { Patients }\end{array}$ & Percentage \\
\hline PCS Rupture & 4 & $66.7 \%$ \\
\hline Parenchymal Laceration & 5 & $83.3 \%$ \\
\hline Ureteric Laceration & 1 & $16.6 \%$ \\
\hline Perinephric Collection & 5 & $83.3 \%$ \\
\hline Periureteric Collection & 1 & $16.6 \%$ \\
\hline $\begin{array}{c}\text { Parenchymal } \\
\text { Devascularisation }\end{array}$ & 4 & $66.7 \%$ \\
\hline Pedicle Avulsion & 0 & 0 \\
\hline \multicolumn{2}{|c|}{ Table 8: Findings in Patients with } \\
Urinary Tract Trauma (N=6) \\
\hline
\end{tabular}

Parenchymal laceration and perinephric collection were most commonly encountered, both occurring in $83.3 \%$ of trauma cases. Parenchymal devascularisation suggested by non-enhancing areas was seen in $66.7 \%$ of the patients.

\begin{tabular}{|c|c|c|}
\hline Type & No. of Patients & Percentage \\
\hline Tuberculous & 3 & $42.9 \%$ \\
\hline Gram Negative & 4 & $57.1 \%$ \\
\hline Total & $\mathbf{7}$ & $\mathbf{1 0 0 \%}$ \\
\hline \multicolumn{2}{|r|}{ Table 9: Aetiology of Infections } \\
Encountered in CT Urography
\end{tabular}

Pelvicalyceal thickening along with ureteric thickening were the most common findings and were noted in all three patients with tuberculous infection. Other findings were focal caliectasis in two patients, parenchymal and ureteric calcification and ureteric calcification, ureteric stricture and infundibular stenosis leading to phantom calyx and caseous abdominal lymph node seen in one patient each.

Focal parenchymal hypodensity and mucosal thickening are seen in $50 \%$ of cases with gram negative infection of the urinary tract. Ureteric thickening and Caliectasis were seen in one patient each. In all four patients, urine culture and microscopy established the diagnosis.

\begin{tabular}{|c|c|}
\hline Anomaly & $\begin{array}{c}\text { No. of } \\
\text { Patients }\end{array}$ \\
\hline Small Pseudoaneurysm of Intrarenal Artery & 1 \\
\hline Isolated Right Renal Vein Thrombosis & 1 \\
\hline $\begin{array}{c}\text { Total } \\
\end{array}$ & 2 \\
\hline \multicolumn{2}{|l|}{$\begin{array}{c}\text { Table 10: Spectrum of Vascular } \\
\text { Anomalies on CT Urography }\end{array}$} \\
\hline
\end{tabular}

In two patients presenting with asymptomatic microscopic haematuria, one of which was a post biopsy status, CT revealed a small traumatic pseudoaneurysm of the lower pole intrarenal segmental artery, while another patient had an isolated renal vein thrombosis, later found out to be due to Protein $\mathrm{C}$ deficiency causing hypercoagulable state. The patient later also developed left lower limb deep venous thrombosis.

\begin{tabular}{|c|c|}
\hline Pathology & $\begin{array}{c}\text { No. of } \\
\text { Patients }\end{array}$ \\
\hline $\begin{array}{l}\text { Advanced Malignancy of Cervix with Direct } \\
\text { Extension to the Base of Bladder }\end{array}$ & 1 \\
\hline $\begin{array}{l}\text { Metastatic Retroperitoneal Lymph Nodal } \\
\text { Mass Directly Invading the Kidney }\end{array}$ & 1 \\
\hline Total & 2 \\
\hline \multicolumn{2}{|c|}{$\begin{array}{l}\text { Table 11: Spectrum of Extraurinary } \\
\text { Tract Pathologies causing Haematuria }\end{array}$} \\
\hline
\end{tabular}

\begin{tabular}{|c|c|c|c|c|c|}
\hline Sl. No. & CT Urography & Sensitivity & Specificity & $\begin{array}{c}\text { Positive } \\
\text { Predictive } \\
\text { Value }\end{array}$ & $\begin{array}{c}\text { Negative } \\
\text { Predictive } \\
\text { Value }\end{array}$ \\
\hline 1. & Urolithiasis & $100 \%$ & - & $100 \%$ & - \\
\hline \multirow{4}{*}{2.} & Urothelial Tract Tumours & & & & \\
\hline & a. Upper Tract & $100 \%$ & $75 \%$ & $83.3 \%$ & $80 \%$ \\
\hline & b. Lower Tract & $66.7 \%$ & $80 \%$ & $66.7 \%$ & $80 \%$ \\
\hline & c. Overall & $86.5 \%$ & $76.7 \%$ & $77.8 \%$ & $80 \%$ \\
\hline 3. & Urinary Bladder Tumours & $80 \%$ & - & $75 \%$ & - \\
\hline 4. & Renal Parenchymal Masses & $100 \%$ & - & $94.1 \%$ & - \\
\hline \multirow{5}{*}{5.} & \multirow[b]{2}{*}{ a. Upper Tract } & & & & \\
\hline & & $91.7 \%$ & $100 \%$ & $100 \%$ & $85.7 \%$ \\
\hline & b. Lower Tract & $60 \%$ & $100 \%$ & $100 \%$ & $60 \%$ \\
\hline & $\begin{array}{c}\text { c. Overall } \\
\end{array}$ & $77.3 \%$ & $100 \%$ & $100 \%$ & $54.5 \%$ \\
\hline & Overall Accuracy in Identifying a Pathology & 93.9\% & $100 \%$ & $100 \%$ & $50 \%$ \\
\hline
\end{tabular}




\section{DISCUSSION}

Haematuria is a common clinical problem with prevalence rate of $9-18 \%$ and can originate from any site along the urinary tract and whether gross or microscopic may be a sign of serious underlying disease including malignancy. The incidence of asymptomatic microscopic haematuria in general population varies from $0.9 \%$ to $21 \% .^{13}$ Although ultrasound is very effective in detecting renal cystic lesions, this modality also has poor sensitivity for detecting solid renal lesions less than $3 \mathrm{~cm} .^{13}$ MRI has been recently used to evaluate the urinary system. ${ }^{14}$ However, the inability of MRI to pick up calcification is an inherent drawback of this modality in its utility in diagnosing urinary pathologies. Also the cost and lack of easy availability restricts its use. At present the use of MR urography is limited to children, pregnant women, in renal insufficiency and in patients with contrast allergy. ${ }^{14}$

The ability of CT urography to evaluate the renal parenchyma as well as the urothelium in a single investigation has prompted many authors to moot it as a potential one stop investigation for the spectrum of urinary tract disorder with haematuria.5,8,9 During this prospective study, 105 patients with haematuria underwent CT Urography at the Department of Radiodiagnosis of our institute over a period of 24 months from November 2009 to October 2011.

Out of the 105 patients referred for CT Urography (CTU), 93 were found to have positive findings on CT urography concerning the high percentage of identifying pathological findings (Sensitivity 93.9\%, positive predictive value 100\% and specificity $100 \%$ ) among the patients with haematuria in our study, it should be under consideration to have CTU as the first line diagnostic tool.

CT Urography is the best diagnostic tool for detection of urolithiasis. ${ }^{15,16}$ and can accurately diagnose the complications associated with the same as well as adequately comment on renal excretory function, which is of prime importance for the treating urologist.

Our CT urography protocol was $87.5 \%$ sensitive and $77.8 \%$ positively predictive for urothelial tract malignancies with these values being $100 \%$ and $83 \%$ for upper tract and $66.7 \%$ and $80 \%$ for lower tract, thus establishing the fact that CT Urography is a highly accurate modality of investigation for upper urothelial tract pathologies with propensity to detect even subtle urothelial tract thickening and hence facilitating detection of malignancies in their early stages. For lower urinary tract, however, the sensitivity of examination would approach nearly $100 \%$ if CT is combined with ureteroscopic examination. The poor sensitivity of CT Urography would be due to relatively poor distension and opacification of lower ureters in some patients. Further refining of CT urography protocols and newer scanners with more detector rows and faster scan times by improving the spatial resolution may settle the issue to some extent.

Our study was $80 \%$ sensitive and $75 \%$ positively predictive in the detection of bladder tumours. Although CT has been shown to detect bladder lesions with sensitivities up to $90-95 \%$ using specialized virtual cystography and reconstruction techniques, our protocol was not routinely performed on patients with haematuria at our institution. Small tumours at the ureteral orifices were missed, possibly due to the normal protrusion that is often seen in that region. Mixing artifacts within the bladder can also result in falsepositive and false-negative interpretations. Despite the improvements in CT spatial resolution, the use of an anatomic imaging approach will not provide the ability to identify the presence of flat bladder tumours, such as carcinoma in situ. Conventional cystoscopy still remains the gold standard for evaluation of the bladder urothelium and patients with haematuria should ideally undergo both CT urography and conventional cystoscopy.

The split-bolus protocol also accurately detected all instances of renal cell carcinoma, which were not previously diagnosed or suspected clinically suggesting that synchronous acquisition of nephrographic and excretory phases does not compromise the ability to visualize the renal parenchyma. However, we also made use of the triple phase protocol with initial acquisition in cortico-medullary phase, so as to stage the tumours once they are detected and such patients did not require any additional study for staging.

However, the benefit of reduced radiation dose to most patients who had no malignancy outweighs the inconvenience of possible reimaging with triple phase protocol to the few patients with malignancy. ${ }^{5}$

We have found that it remains imperative that the axial source images are viewed and interpreted and that appropriate tailored window and level settings be used when evaluating the collecting system and ureters, so that dense intraluminal contrast material does not obscure fine urothelial detail and potentially small urothelial lesions. Having said so, the 3D reformatted images are imperative in making a diagnosis and also to convey information to the referring clinicians in a more user friendly manner.

Developmental anomalies of the urinary tract along with their complications are very well depicted by CT urography. CT urography precisely grades urinary tract trauma playing a crucial role in the management of such patients.

CT urography plays an important role in detecting the features as well as complications of both tuberculous and pyogenic infections of the urinary tract.

In summary, we have shown that a split-bolus protocol for CT urography can be used successfully to evaluate for urinary tract calculi, renal abnormalities and urothelial lesions in one simple, non-invasive examination. Although this study did not include a direct comparison between this technique and other MCDT urography protocols, our data suggests that the sensitivities and specificities in detecting a variety of abnormalities are comparable to other protocols. The splitbolus protocol reduces radiation dose to patients and results in a smaller number of images for interpretation compared with other MDCT urography protocols. Given the significant advantages of this protocol, we believe that it has potential as an alternative to existing MDCT urography protocols and IVU for the evaluation of the urinary tract.

\section{LIMITATIONS}

1. Lack of adequate contrast opacification and distention of the urinary tract. In such cases, subtle intrinsic lesions causing tiny filling defects may be missed. Though various modifications to increase ureteric opacification are being tried, a consensus is yet to be reached regarding the best method.

2. Radiation dose remains a concern for multiphase CT urography. ${ }^{16}$ However, two phase CT urography protocol used in this study significantly reduces the radiation dose. 
3. Accuracy is limited for lower urinary tract pathologies.

\section{CONCLUSIONS}

- Multidetector CT urography detects with high accuracy the entire spectrum of urinary tract pathologies causing haematuria.

- The two phase protocol evaluates both the renal parenchymal and urothelial pathologies in a single investigation reducing significantly the radiation dose to the patient.

- Thus, multidetector CT urography has the potential to become a one stop shop for evaluation of urinary tract, especially in cases of haematuria. ${ }^{17}$

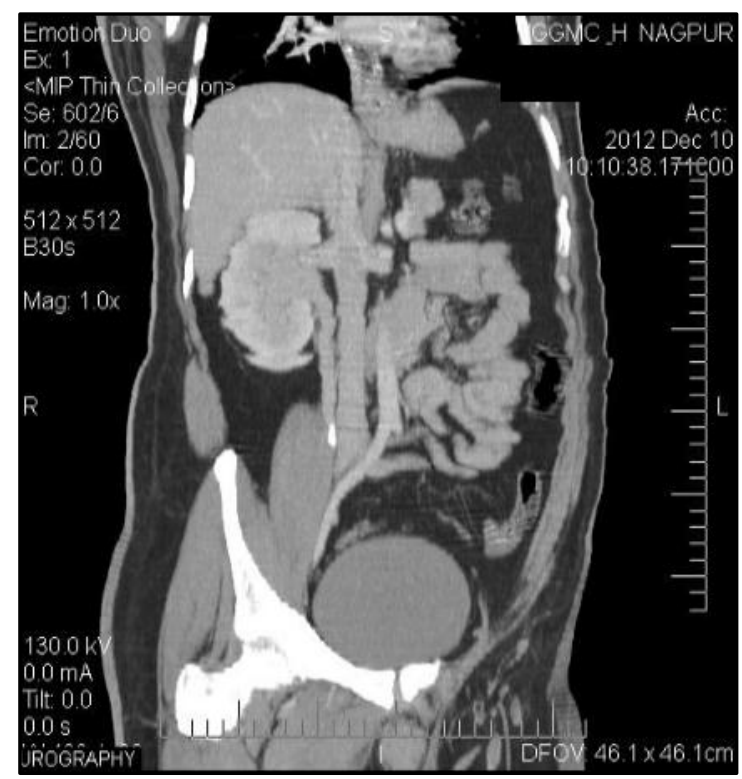

Case 1: 3D Reformatted Coronal MIP Image showing the Right Ureteric Calculus, causing Upstream Obstructive Hydronephroureterosis and Normal Excretion of Right Kidney Normal Excretion of Right Kidney

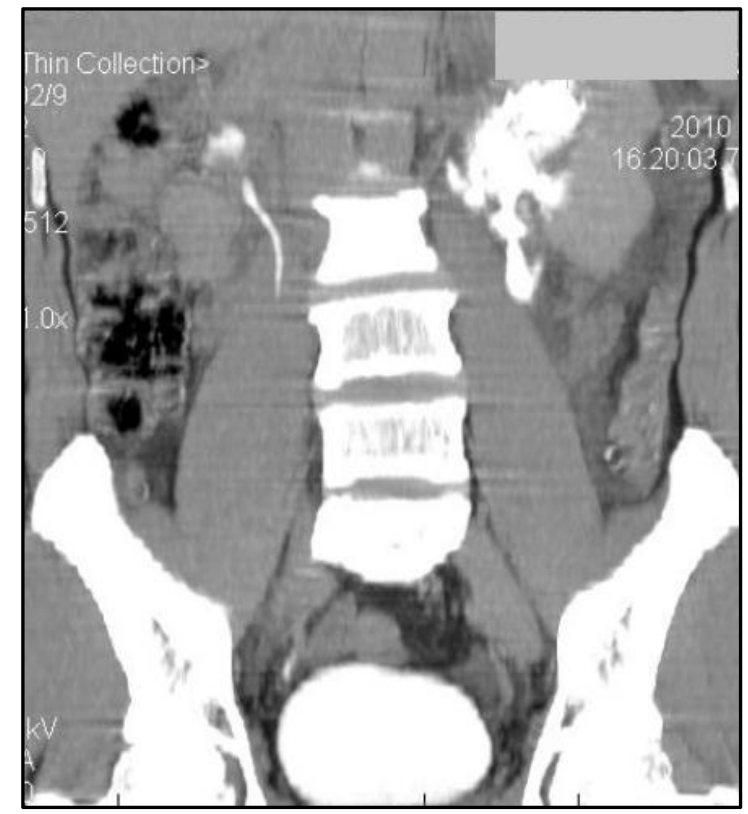

Case 2: Acute Obstruction due to Left Ureteric Calculus

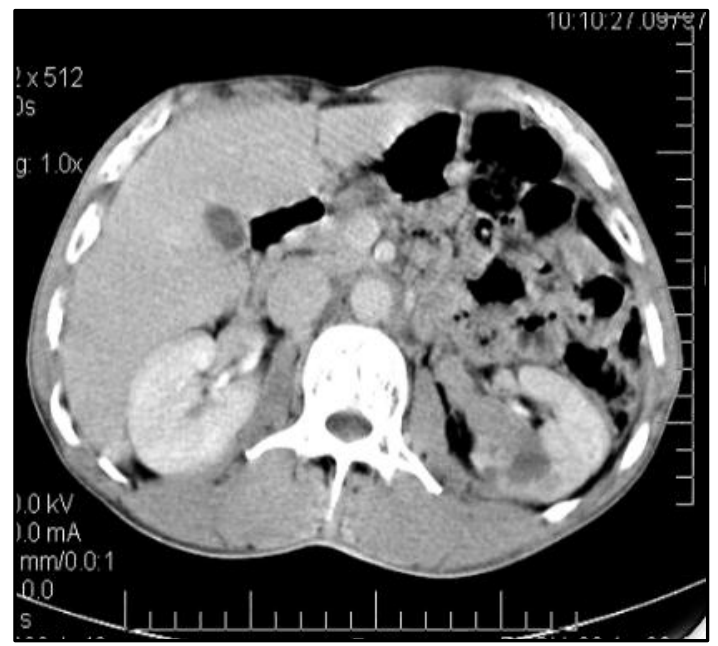

Case 3: Axial Image in Patient showing Infiltrating

Left Renal Pelvic Hypodense Lesion with Deranged Excretory Function Renal Pelvicalyceal TCC

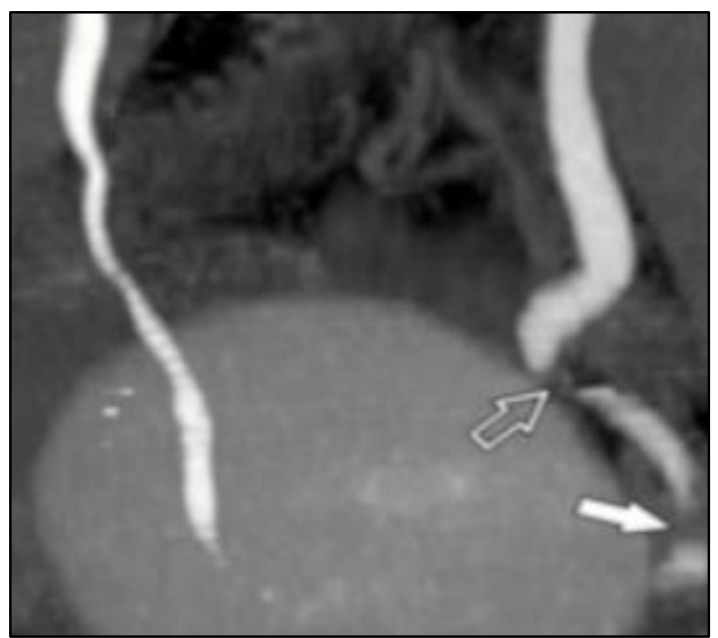

Case 4: Coronal Reconstructed Thin MPR Image showing Stenosing Lesion of the Left Ureter with Periureteric Soft Tissue (White Arrow). Ureteric Peristalsis shown by Open Arrow. Ureteric TCC

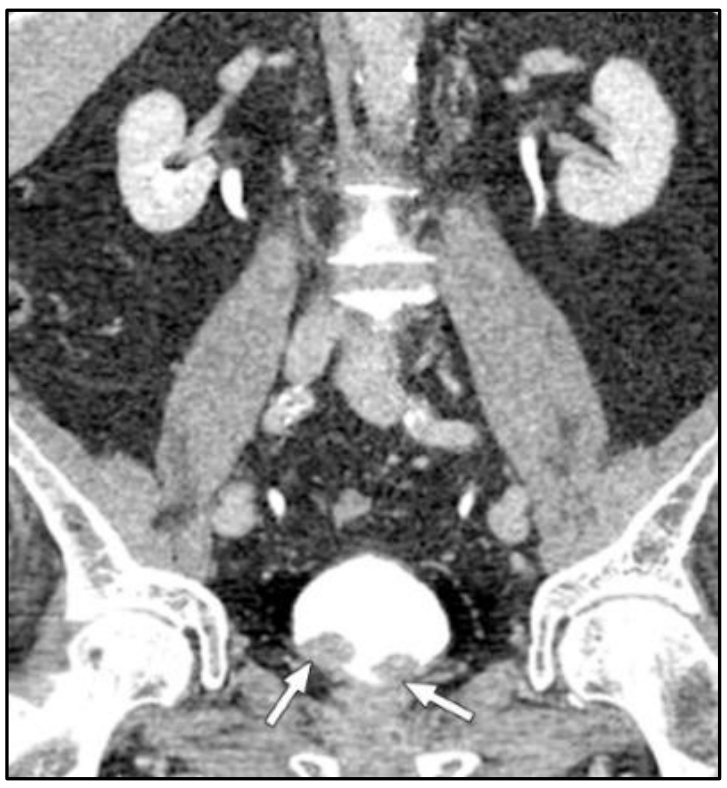

Case 5: Coronal Reformatted MPR Image showing Two Nodular Hypodense Lesions at the Base of Bladder Multifocal Papillary TCC 


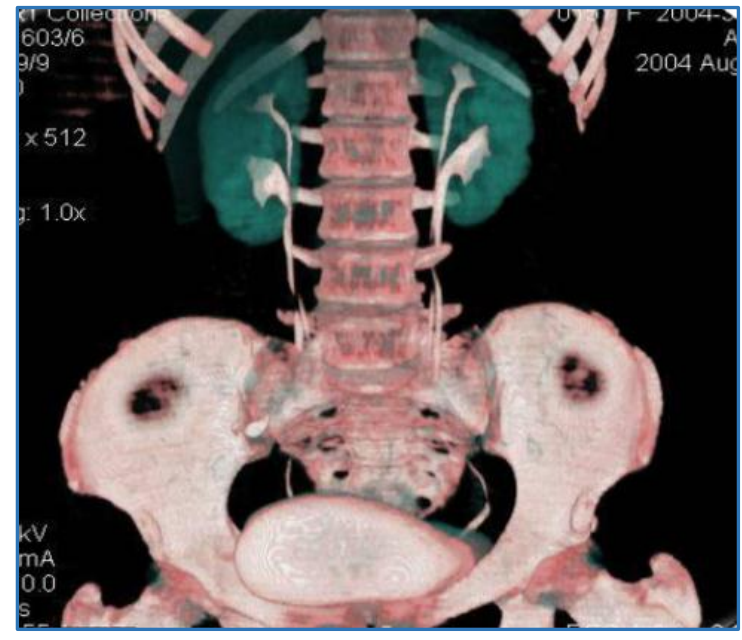

Case 6: Double Moiety of Ureters as seen on VRT Images

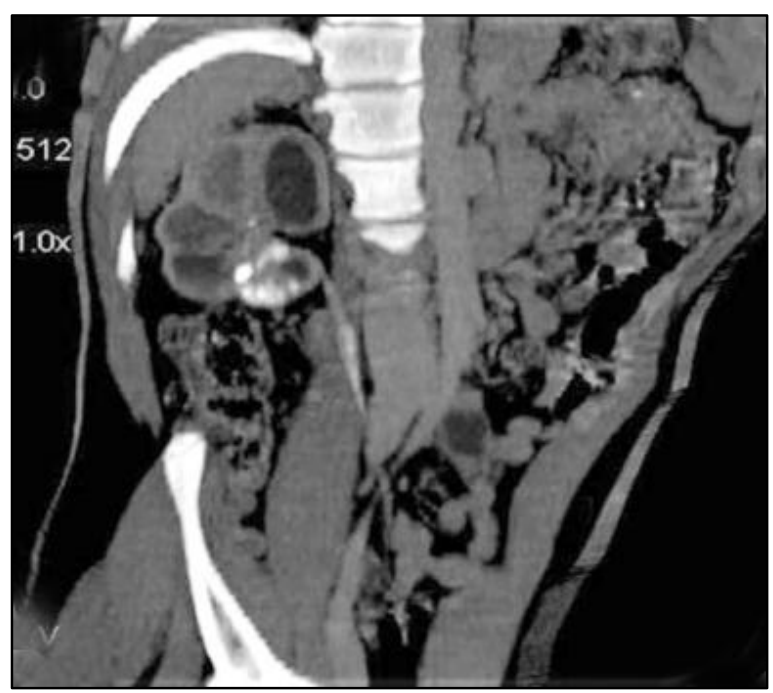

Case 7: Oblique MPR Image showing Hydronephrotic Kidney with Parenchymal and Ureteric Calcifications

\section{Case 8}

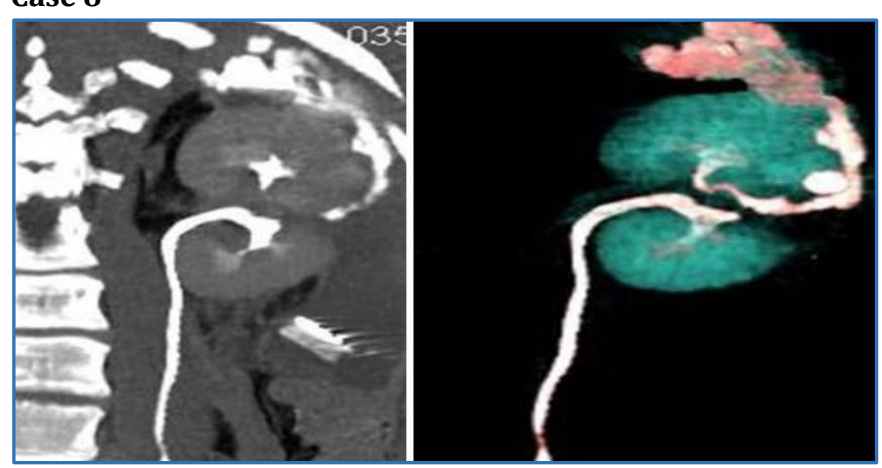

\section{Left Renal Trauma}

a) Coronal MPR image showing a laceration through the interpolar region with contrast extravasation and perirenal haematoma.

b) Volume rendered coronal reformatted image of the same. AAST Grade III renal injury. (AAST - American Association of Surgery in Trauma).

\section{REFERENCES}

1. Maher MM, Kalra MK, Rizzo S, et al. Multidetector CT urography in imaging of the urinary tract in patients with haematuria. Korean J Radiol 2004;5(1):1-10.

2. Choyke PL. Radiologic evaluation of hematuria: guidelines from the American college of radiology; appropriateness criteria. Am Fam Physician 2008;78(3):347-52.

3. Prokop M. CT of the genitourinary tract. In: Prokop $M$, Galanski M, eds. The Kidneys. Stuttgart: Thieme 2003:639-81.

4. Silverman SG, Leyendecker JR, Amis ES. What is the current role of CT urography and MR urography in the evaluation of the urinary tract. Radiology RSNA 2009;250(2):309-23.

5. Noroozian M, Cohan RH, Caoili EM, et al. Multislice CT urography: state of the art. Br J Radiol 2004;77 Spec No 1:S74-86.

6. Silverman SG, Cohan RH. CT urography: an atlas. Philadelphia: Lippincott, Williams and Wilkins 2007:1-10.

7. Heidenreich A, Desgrandschamps F, Terriar F. Modern approach of diagnosis and management of acute flank pain. Eur Urol 2002;41(4):351-62.

8. Chai RY, Jhaveri K, Saini S, et al. Comprehensive evaluation of patients with hematuria on multi-slice computed tomography scanner: protocol design and preliminary observations. Australas Radiol 2001;45(4):536-8.

9. Kalra MK, Maher MM, Sahani DV, et al. Current status of multidetector computed tomography urography in imaging of the urinary tract. Curr Probl Diagn Radiol 2002;31(5):210-21.

10. Chow LC, Kwan SW, Olcott EW, et al. Split bolus MDCT urography with synchronous nephrographic and excretory phase enhancement. AJR Am J Roentgenol 2007;189(2):314-22.

11. Sanyal R, Deshmukh A, Sheorain SV, et al. CT urography: a comparison of strategies for upper urinary tract opacification. Eur Radiol 2007;17(5):1262-6.

12. Grossfeld GD, Litwin MS, Wolf JS, et al. Evaluation of asymptomatic microscopic hematuria in adults: the American urological association best practice policy. Part I. Definition, detection, prevalence, and etiology. Urology 2001;57(4):599-603.

13. Kawashima A, Glockner JF, King BF. CT urography and MR urography. Radiol Clin N Am 2003;41(5):945-61.

14. Jamis-Dow CA, Choyke PL, Jennings $\mathrm{SB}$, et al. Small $(<$ or $=3 \mathrm{~cm}$ ) renal masses: detection with CT versus US and pathologic correlation. Radiology 1996;198(3):785-8.

15. Levine JA, Neitlich J, Verga $M$, et al. Ureteral calculi in patients with flank pain: correlation of plain CT with unenhanced helical CT. Radiology 1997;204(1):27-31.

16. Herts BR. The current status of CT urography. Crit Rev Comput Tomogr 2002;43(3):219-41.

17. Joffe SA, Servaes S, Okon S, et al. Multi-detector row CT urography in the evaluation of hematuria. Radiographics 2003;23(6):1441-55. 